OPEN ACCESS

Edited by:

Rengyun Liu,

Johns Hopkins University,

United States

Reviewed by:

Jisha Antony,

University of Otago, New Zealand

Konrad Huppi,

National Cancer Institute (NCl),

United States

*Correspondence:

Olorunseun O. Ogunwobi

ogunwobi@genectr.hunter.cuny.edu

Specialty section: This article was submitted to

Cancer Genetics,

a section of the journal

Frontiers in Oncology

Received: 22 May 2019 Accepted: 13 August 2019

Published: 27 August 2019

Citation:

Ogunwobi OO and Kumar A (2019) Chemoresistance Mediated by ceRNA

Networks Associated With the PVT1

Locus. Front. Oncol. 9:834

doi: 10.3389/fonc.2019.00834

\section{Chemoresistance Mediated by ceRNA Networks Associated With the PVT1 Locus}

\author{
Olorunseun O. Ogunwobi ${ }^{1,2 *}$ and Adithya Kumar ${ }^{1}$ \\ ${ }^{1}$ Department of Biological Sciences, Hunter College of the City University of New York, New York, NY, United States, ${ }^{2}$ Joan \\ and Sanford I. Weill Department of Medicine, Weill Cornell Medicine, Cornell University, New York, NY, United States
}

Competitive endogenous RNA (ceRNA) networks have emerged as critical regulators of carcinogenesis. Their activity is mediated by various non-coding RNAs (ncRNAs), including long non-coding RNAs and microRNAs, which competitively bind to targets, thereby modulating gene expression and activity of proteins. Of particular interest, ncRNAs encoded by the 8q24 chromosomal region are associated with the development and progression of several human cancers, most prominently IncPVT1. Chemoresistance presents a significant obstacle in the treatment of cancer and is associated with dysregulation of normal cell processes, including abnormal proliferation, differentiation, and epithelial-mesenchymal transition. CeRNA networks have been shown to regulate these processes via both direct sponging/repression and epigenetic mechanisms. Here we present a review of recent literature examining the contribution of ncRNAs encoded by the PVT1 locus and their associated ceRNA networks to the development of resistance to common chemotherapeutic agents used to treat human cancers.

Keywords: PVT1, IncRNA, ceRNA, miRNA, chemoresistance, carcinogenesis, 8q24, cancer

\section{INTRODUCTION}

Competitive endogenous RNA (ceRNA) networks have increasingly been found to play an important role in carcinogenesis (1). These networks are characterized by "sponging" activity, whereby non-coding RNAs (ncRNAs) competitively bind and repress targets, often demonstrating reciprocal activity $(2,3)$. Long non-coding RNAs (LncRNAs) are generally classified as ncRNA transcripts 200 nucleotides or greater in length and are involved in both transcriptional and post-transcriptional gene regulation, including genome organization $(4,5)$. Several lncRNAs have been shown to play a role in carcinogenesis, a prominent example being lncPVT1, which is homologous to the mouse plasmacytoma variant translocation 1 gene.

PVT1 is located downstream of proto-oncogene MYC on chromosomal region 8q24, a known cancer susceptibility locus (6). MYC expression has been shown to be highly reliant on PVT1$P V T 1$ is increased in nearly $98 \%$ of cancers displaying overexpression of MYC (7). It was recently was found that the PVT1 promoter can behave as a tumor suppressor DNA boundary element by competing with the MYC promoter in cis for shared enhancers within the gene locus (8). LncPVT1 can also regulate several downstream components of the MYC pathway (9). Their complex relationship emphasizes the importance of this gene locus to cancer progression.

MicroRNAs (miRNAs) are small ncRNAs, roughly 18-25 nucleotides in length (10). miRNAs can induce translational repression of target mRNA by recruiting the RNA-induced silencing complex (RISC) and binding to miRNA response elements (MREs) (11). LncRNA have been shown 
to reduce miRNA-mediated translational repression by sequestering miRNAs or competitively binding targets, for example, lncPVT1 has been shown to regulate the activity of its own miRNA transcripts $(12,13)$. The PVT1 gene encodes for six microRNAs: miR-1204, miR-1205, miR-1206, miR-1207-3p, miR-1207-5p, and miR-1208 (14, 15). These transcripts have been shown to participate in ceRNA networks in many cancers, exerting both oncogenic and tumor suppressive roles. Circular RNAs (circRNAs) represent another class of ncRNAs that are formed by bonding of the $3^{\prime}$ and $5^{\prime}$ ends of RNA (5).

Chemotherapy resistance presents a significant impediment to successful treatment of most cancers, leading to diminished survival and higher recurrence rates. Cancers can exhibit either primary/intrinsic chemoresistance, for example, via tumor heterogeneity, or secondary/acquired chemoresistance via mechanisms such as target inactivation or alteration, drug efflux, cell death inhibition, DNA damage repair, epigenetics, mutations, or epithelial-mesenchymal transition (EMT) (16).

This paper aims to present a review of primary literature examining the role of lncRNA PVT1, associated miRNA transcripts, and their respective ceRNA networks in the development of resistance to common chemotherapeutic agents used to treat human cancers. This area of research is a promising target for the development of new chemotherapeutics or enhancement of existing treatment regimens.

\section{BREAST CANCER}

Breast cancer remains the leading cause of cancer death among women under the age of 60 (17). Triple-negative breast cancers (TNBCs) are among the most difficult to treat and have the worst prognosis among breast cancer subtypes due to the lack of available targeted therapy (18). Taxane-based chemotherapy remains the primary treatment approach for TNBC and metastatic breast cancer. Despite their general success, response rates for paclitaxel and docetaxel are low in many subtypes $(19,20)$.

MiR-1207 has been found to be elevated in several cancers, including young breast cancer patients (21). Leucine zipper tumor suppressor gene 1 protein (LZTS1), a tumor suppressor, was found to be downregulated in paclitaxel-resistant breast cancer (22). MiR-1207-5p can promote chemoresistance in TNBC cells by inhibiting LZTS1, thereby decreasing cell growth arrest and apoptosis in response to paclitaxel (23). Furthermore, there was downregulation of Bax and upregulation of $\mathrm{Bcl}-2$, pro-apoptotic and anti-apoptotic genes, respectively.

Although there is evidence for a regulatory role for miR1207-5p in TNBC, several questions remain. LZST1 was chosen due to its role as a tumor suppressor, but other apoptotic pathways may also be targeted by miR-1207-5p. Additionally, alternate mechanisms may contribute to overall drug resistance that were not studied here, including proliferative and drug efflux pathways, which are known to be active in breast cancer $(24,25)$.

MiR-1207-5p has also been found to negatively regulate transcription factor STAT6 in invasive breast cancer, leading to disinhibition of CDKN1A/B, increased proliferation, and cell cycle progression (26). MiR-1204 has been shown to promote tumorigenesis, EMT, and metastasis in breast cancer by targeting the vitamin D receptor gene (VDR) (27). The role of vitamin D signaling in cancer is well-studied; calcitriol, the active metabolite of vitamin $\mathrm{D}$, can improve chemosensitivity in breast cancer (28-31). Ablation of VDR has also been shown to promote breast tumorigenesis in mice $(32,33)$. The aforementioned studies are promising, and future research should further explore possible ceRNA networks involving miR-1204 and miR-1207 in breast cancer.

\section{CERVICAL CANCER}

Cervical cancer (CC) is the second most common cancer among women aged 20-39 years in the United States (17). HPV infection has been shown to contribute to its development and coincide with $99.7 \%$ of cases (34). Two viral HPV oncoproteins, E6 and E7, have been implicated in tumorigenesis via degradation of tumor suppressor $\mathrm{p} 53$ and interaction with $\mathrm{pRb}$, respectively (35). Paclitaxel-based chemotherapy is commonly used in conjunction with cisplatin as first-line chemotherapy for CC. (36).

LncPVT1 can regulate miR-195 via both epigenetic and sponging mechanisms, thereby disinhibiting downstream activation of SMAD3, promoting EMT, and inducing paclitaxel resistance in CC (37). The MiR-195 was previously been shown to behave as a tumor suppressor in CC by repressing SMAD3, a member of the SMAD family of transcription factors which mediate the TGF- $\beta$ family of cytokines, responsible for cell proliferation and differentiation (38, 39). MiR-195 and lncPVT1 have reciprocal sponging activity, whereby miR-195 overexpression reduces expression of lncPVT1 and PVT1 knockdown increases miR-195 expression (37). Overexpression of miR-195 or PVT1 knockdown resulted in downregulation of mesenchymal markers (vimentin, fibronectin) and upregulation of epithelial markers (E-cadherin) in response to paclitaxel treatment.

LncPVT1 can also epigenetically regulate miR-195 by inducing $\mathrm{H} 3 \mathrm{~K} 27 \mathrm{me} 3$ methylation in the miR-195 promoter region via recruitment of EZH2. LncPVT1 was also shown recruit EZH2 in lung, hepatocellular, and thyroid cancers (4042). Additionally, knockdown of HPV16 E7 decreased levels of lncPVT1 and increased levels of miR-195. This ceRNA network involving lncPVT1 and miR-195 in cervical cancer characterizes the typical complex pathway mediating chemoresistance in many cancers (Figure 1).

Previous studies have shown related roles for lncPVT1 in CC. It can sponge miR-424 to promote cell proliferation, invasion and migration, as well as regulate expression of miR-200b by recruiting EZH2 $(43,44)$. LncRNA HOTAIR has also been shown to interact with HPV16 E7 to potentially contribute to cervical carcinogenesis (45). Approximately 14 other lncRNAs have been shown to be involved in CC and there is significant research to be done concerning their roles in chemoresistance, including overlap with lncPVT1 (46).

\section{LUNG CANCER}

Lung cancer remains the most prevalent cancer among both sexes (17). Non-small cell lung cancer (NSCLC) accounts for 


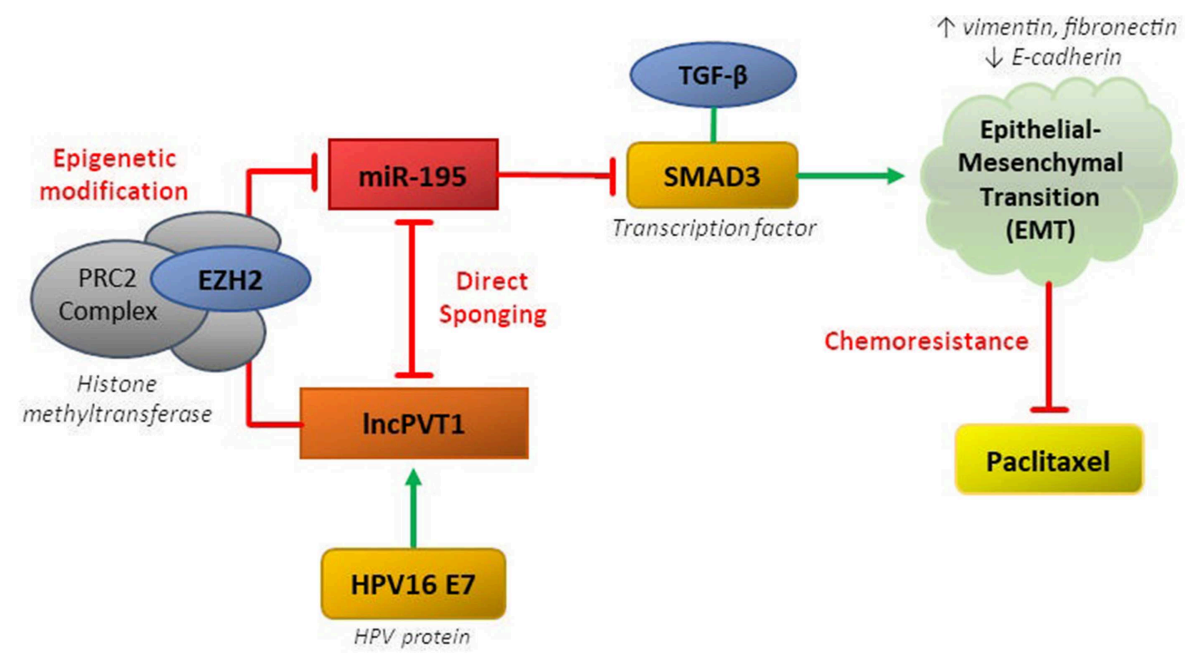

FIGURE 1 | CeRNA networks involving IncPVT1 and its associated transcripts are generally mediated by two mechanisms: (1) direct sponging of other RNA transcripts/proteins or (2) epigenetic modification. Both of these mechanisms have been shown to be active in regulating chemoresistance in cervical cancer.

approximately $90 \%$ of lung cancers and the majority of patients are diagnosed at later stages (47). Cisplatin is a common first-line adjuvant chemotherapeutic for NSCLC, however many cancers are chemoresistant and have poor response to treatment (48-50).

LncPVT1 can promote cisplatin resistance in NSCLC by acting as a ceRNA for miR-216b and upregulating downstream Beclin-1 (51). Levels of lncPVT1 were significantly increased, while levels of miR-216b were reduced, in the A549/DDP cisplatin-resistant NSCLC cell line. PVT1 knockdown promoted apoptosis and suppressed autophagy. Beclin-1 plays a complex role in regulating both autophagy and apoptosis and it was found to be negatively associated with tumor recurrence rate in NSCLC $(52,53)$.

Other ncRNA have been shown to modulate chemoresistance by targeting Beclin-1. Mir-216b can modulate vemurafenib sensitivity in melanoma by targeting Beclin-1 and associated proteins (UVRAG and ATG5) (54). Negative regulation of Beclin-1 by miR-30d in anaplastic thyroid carcinoma (ATC) has been shown to suppress autophagy and promote apoptosis, and lower levels of miR-30d in ATC cells were correlated with cisplatin-resistance (55). The role of lncPVT1 in these contexts has not been studied.

LncPVT1 can behave as a ceRNA for at least four other miRNAs in NSCLC: miR-195, miR-199-5p, mir-424-5p, and miR497 (56-60). Regulatory axes containing miR-195 and miR-424$5 \mathrm{p}$ are of particular interest since they have been shown to mediate radiosensitivity, a crucial component of multi-modal lung cancer treatment $(56,59)$. PVT1-derived miR-1204 has also been shown to promote cell proliferation in NSCLC by regulating paired-like homeodomain 1 (PITX1), a member of the RIEG/PITX family involved in organ development (61). LncPVT1 can also epigenetically downregulate large tumor suppressor kinase 2 (LATS2) in NSCLC via recruitment of EZH2 and methylation of the LATS2 promoter, similar to the mechanism in cervical cancer (40). Further research is needed to uncover the molecular targets of other microRNA and potential mechanisms contributing toward chemoresistance in lung cancer.

\section{OSTEOSARCOMA}

Osteosarcoma is a rare sarcoma with global incidence of 3.4 cases per million, occurring mostly among younger age groups (62). Five-year survival has improved significantly since the introduction of chemotherapeutics, but high grade and metastatic patients still have dismal outcomes. Doxorubicin and cisplatin are ubiquitous components of osteosarcoma regimens, while gemcitabine is primarily used in patients with unresectable or recurrent disease $(62,63)$.

LncPVT1 can promote gemcitabine resistance in osteosarcoma by serving as a ceRNA of miR-152 and disinhibiting c-MET and the downstream PI3K/AKT pathway (64). PVT1 was upregulated and miR-152 was downregulated in the MG63/DOX chemoresistant osteosarcoma cell line. Overexpression of PVT1 attenuated gemcitabinemediated inhibition of tumor growth. Previous studies have shown that c-MET mediates chemoresistance to cisplatin in osteosarcoma and that miR-152 acts as a tumor suppressor by targeting c-MET in oral squamous cell carcinoma $(65,66)$.

Alternatively, circRNA PVT1 may contribute to doxorubicin and cisplatin resistance in osteosarcoma by regulating multidrug resistance protein 1 (MDR1) (67). CircRNA PVT1 knockdown was shown to decrease levels of MDR1 and reverse doxorubicin and cisplatin resistance in chemoresistant cell lines. However, the specific mechanism of regulation was not clearly demonstrated. LncPVT1 can also alter glucose metabolism in osteosarcoma by acting as a ceRNA for miR-497 and disinhibiting hexokinase 2, consequently increasing glucose uptake and lactate production (68). It can also inhibit apoptosis, cell cycle arrest, and invasion/migration by acting as a ceRNA for of miR-195 and 
upregulating BCL2, CCND1, and FASN, respectively, in the U2OS cell line (69).

\section{PANCREATIC CANCER}

Pancreatic cancer (PC) is the fourth most common cancer in the United States (17). The typical adjuvant chemotherapeutic regimen generally consists of either gemcitabine or 5-flurouracil and leucovorin (70). Previous research indicated that PVT1 overexpression may induce gemcitabine resistance in PC (71). Meanwhile, overexpression of miR-1207-3p and miR-1207-5p inhibited proliferation and increased apoptosis after gemcitabine treatment. C-Src was identified as a potential target of miR-1207$5 p$ and experiments confirmed that miR-1207-5p could reduce levels of c-Src in both PC cell lines and tissue. MiR-1207-3p was similarly shown to target RhoA, which has been shown to play a complex role in carcinogenesis $(13,72)$. Future research can hopefully elucidate the role of these pathways and their downstream targets in contributing to chemoresistance.

Additionally, gemcitabine treatment was shown to upregulate expression of miRNA processing enzymes, Drosha and DGCR8, leading to increased processing of lncPVT1 into mature miR1207-5p/3p transcripts, thereby inhibiting downstream targets $(13,64)$. This unique regulatory relationship of differential processing of lncPVT1 has not been well-studied with respect to chemoresistance. Similar to its activity in cervical cancer, lncPVT1 can also upregulate the SMAD/TGF- $\beta$ pathway and promote EMT in PC, although the mechanism by which this occurs has not yet been uncovered (73).

\section{OTHER CANCERS}

There is evidence that lncPVT1 and its associated miRNA transcripts can modulate chemoresistance in several other cancers, although their molecular targets have not been identified or their role in influencing response to chemotherapeutics has not yet been studied. It is critical to further study the role of these pathways in chemoresistance.

Gallbladder cancer (GBC) is rare in the United States, but prevalent among certain populations, such as North and South American Indians (74). GBC is overwhelmingly diagnosed at later stages and 5-year survival remains low (75). Cisplatin is a component of first-line therapy and resistance can impede treatment (76). MiR-1207-5p has been shown to decrease cisplatin sensitivity in GBC by an unknown mechanism (77). Levels of MiR-1207-5p correlated with both proliferative and apoptotic markers in this study, inconsistent with a uniform role in GBC. LncPVT1 can act as a ceRNA for miR-143 in GBC, disinhibiting hexokinase 2 , and promoting cell proliferation invasion and migration $(78,79)$. Hexokinase 2 has also been shown to be regulated by miR-143 in other cancers, including colon, prostate, and breast (80). It is important to evaluate the extent these independent pathways may contribute to chemoresistance in GBC.

Hepatocellular carcinoma (HCC) is the fifth-most commonly diagnosed cancer globally, but accounts for a disproportionate amount of cancer-related deaths due to its difficult to treat nature $(17,81)$. Although surgical resection, radiofrequency ablation, and transplantation represent curative approaches for

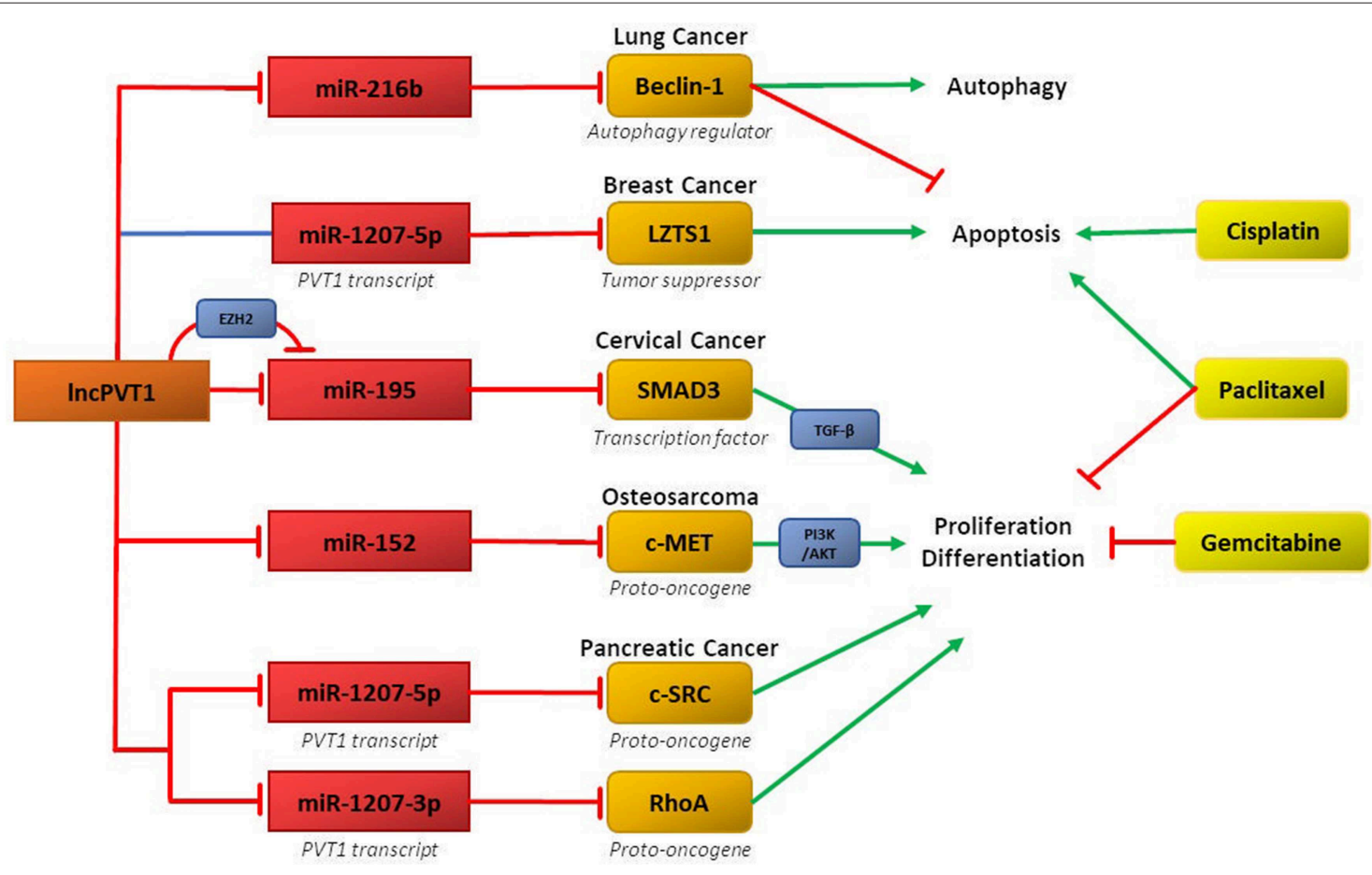

FIGURE 2 | LnCPVT1 and its associated microRNAs induce chemoresistance in various cancers by regulating oncogenes or tumor suppressor genes. Affected downstream pathways include the TGF- $\beta$ and PI3K-AKTpathways. Also depicted is epigenetic inhibition of target genes via EZH2. 
early stage cancers, there is a lack of systemic therapy available for more advanced cases (82). LncPVT1 has been shown to be upregulated in HCC tissues and associated with recurrence (83). LncPVT1 can serve as a ceRNA for miR-186-5P, thereby disinhibiting downstream yes-associated protein 1 (YAP1) to promote tumorigenesis in HCC (84). LncPVT1 can also recruit EZH2 to stabilize MDM2 and repress tumor suppressor p53 in HCC (42). MiR-424-5p is yet another proposed ceRNA target of PVT1, although further research are needed to demonstrate in vitro interaction (85).

Nasopharyngeal carcinoma (NPC) is a relatively rare cancer in the United States but has increased incidence in parts of Southern China $(17,86,87)$. Typically, radiotherapy alone is used in treatment of early-stage NPC, but advanced disease usually necessitates the use of chemotherapy (88). MiR-1204 was shown to be downregulated in paclitaxel-resistant NPC cell lines, and restoration of miR-1204 was shown to resensitize NPC cells to paclitaxel in vitro and inhibit tumor growth in vivo (89). While there is evidence that miR-1204 can modulate paclitaxelresistance in NPC, a molecular target has not yet been identified and the role of other ncRNA from the PVT1 locus has not been studied.

Ovarian cancer (OC) is the fifth leading cause of cancerrelated death among women in the United States and chemoresistance plays a significant role in treatment failure in high-grade and recurrent subtypes (17, 90-92). MiR-1207 was upregulated in $\mathrm{OC}$ tissues and shown to target negative regulators of $\mathrm{Wnt} / \beta$-catenin signaling pathway, including SFRP1, AXIN2, and ICAT, thereby promoting development of ovarian cancer stem cell-like traits (93). Previous studies have shown that genes involved in the Wnt signaling pathway are associated with chemoresistance in OC, highlighting the need for further research regarding the role of miR-1207 and related ncRNA in this context $(94,95)$.

Prostate cancer (PCa) is the second-most commonly diagnosed cancer among men $(17,81)$. Androgen-deprivation is the most common first-line therapy used in the treatment of PCa and the development of androgen-independent or castrationresistant PCa presents a significant obstacle to treatment $(96,97)$. MiR-1207-3p was found to be underexpressed in PCa cell lines and shown to target fibronectin type II domain containing 1 (FNDC1), thereby leading to downregulation of fibronectin 1 (FN1) and loss of androgen receptor expression (98). Future research should study the effects of miR-1207-3P in augmenting androgen-deprivation therapies. Overexpression of LncPVT1 was shown to be correlated with epigenetic silencing of miR-146a and increased cell survival in PCa (99). The mechanism by which this epigenetic regulation occurs was not identified and the influence on chemoresistance has not been studied.

Thyroid cancer (TC) is the ninth-most commonly diagnosed cancer worldwide, with a threefold higher incidence among women $(17,81)$. Several studies have implicated PVT1 in thyroid cancer and have shown it is significantly upregulated $(100,101)$. LncPVT1 acts as a ceRNA for miR-30b in papillary thyroid carcinoma (PTC), thereby disinhibiting IGFR1 and promoting cell proliferation, invasion, migration and EMT (102). LncPVT1 has also been shown to recruit EZH2 to reduce activity of the thyroid-stimulating hormone receptor (TSHR) in TC (41). These results are interesting although their significance in chemoresistance is not well-understood and warrants further study.

\section{CONCLUSION}

Recent research demonstrates that ceRNA networks involving lncPVT1 and its associated miRNAs can mediate chemoresistance in several cancers (Figure 2). The primary regulatory motif involves $\operatorname{lncPVT} 1$ acting as a ceRNA for specific miRNA and consequently disinhibiting downstream genes and proteins involved in promoting chemoresistance, such as anti-apoptotic proteins, cell cycle regulators, and mediators of EMT. Interestingly, differential processing of lncPVT1 in various cancers can also increase or decrease levels of PVT1-derived miRNAs, which can inhibit downstream targets. Alternatively, lncPVT1 or its associated transcripts can recruit epigenetic modifiers, such as EZH2, to modify expression of target genes.

In addition to the role of lncPVT1 in cisplatin resistance in gallbladder, lung, and osteosarcoma discussed here, lncPVT1 has also been shown to promote cisplatin resistance in gastric and colorectal cancers, although the molecular mechanisms and associated ceRNA networks have not been studied thoroughly and are promising for further research $(103,104)$. We also presented the first study implicating circRNA PVT1 in chemoresistance in osteosarcoma (67). It has previously been shown to have ceRNA activity in colorectal, gastric, and nonsmall cell lung cancers (105-107), although its chemoresistant role in other cancers has not been well-studied.

The majority of chemotherapeutics discussed here represent first-line therapies for their respective cancers, such as paclitaxel and cisplatin. However, often the most difficult to treat cases involved treatment with second- or third-line therapies, and thus future research should also consider the potential role of ncRNA to enhance the efficacy of these drugs.

The PVT1 locus in particular is a promising area of study in terms of the discovery of new ceRNA networks in cancer. Further identification of regulatory networks could potentially introduce a new class of targeted therapeutics. Additional roles could include the co-delivery of drugs to potentiate existing therapeutics, especially difficult to treat chemoresistant cancers involving second- or -third line treatments.

\section{AUTHOR CONTRIBUTIONS}

AK wrote the first draft of the manuscript. OO reviewed, edited, and approved final version of the manuscript.

\section{FUNDING}

OO was supported by National Cancer Institute grant \# 1 U54CA221704-01A1. 


\section{REFERENCES}

1. Yang C, Wu D, Gao L, Liu X, Jin Y, Wang D, et al. Competing endogenous RNA networks in human cancer: hypothesis, validation, and perspectives. Oncotarget. (2016) 7:13479-90. doi: 10.18632/oncotarget.7266

2. Salmena L, Poliseno L, Tay Y, Kats L, Pandolfi PP. A ceRNA hypothesis: the Rosetta Stone of a hidden RNA language? Cell. (2011) 146:353-8. doi: 10.1016/j.cell.2011.07.014

3. Anastasiadou E, Jacob LS, Slack FJ. Non-coding RNA networks in cancer. Nat Rev Cancer. (2018) 18:5-18. doi: 10.1038/nrc.2017.99

4. Ulitsky I, Bartel DP. lincRNAs: genomics, evolution, and mechanisms. Cell. (2013) 154:26-46. doi: 10.1016/j.cell.2013.06.020

5. Lasda E, Parker R. Circular RNAs: diversity of form and function. RNA. (2014) 20:1829-42. doi: 10.1261/rna.047126.114

6. Grisanzio C, Freedman ML. Chromosome 8q24-Associated cancers and MYC. Genes Cancer. (2010) 1:555-9. doi: 10.1177/1947601910381380

7. Tseng YY, Moriarity BS, Gong W, Akiyama R, Tiwari A, Kawakami H, et al. PVT1 dependence in cancer with MYC copy-number increase. Nature. (2014) 512:82-6. doi: 10.1038/nature13311

8. Cho SW, Xu J, Sun R, Mumbach MR, Carter AC, Chen YG, et al. Promoter of IncRNA gene PVT1 Is a tumor-suppressor DNA boundary element. Cell. (2018) 173:1398-412 e22. doi: 10.1016/j.cell.2018.03.068

9. Jin $\mathrm{K}$, Wang $\mathrm{S}$, Zhang $\mathrm{Y}, \mathrm{Xia} \mathrm{M}, \mathrm{Mo} \mathrm{Y}, \mathrm{Li} \mathrm{X}$, et al. Long noncoding RNA PVT1 interacts with MYC and its downstream molecules to synergistically promote tumorigenesis. Cell Mol Life Sci. (2019). doi: 10.1007/s00018-019-03222-1. [Epub ahead of print].

10. Bartel DP. MicroRNAs: genomics, biogenesis, mechanism, and function. Cell. (2004) 116:281-97. doi: 10.1016/S0092-8674(04)00045-5

11. Guil S, Esteller M. RNA-RNA interactions in gene regulation: the coding and noncoding players. Trends Biochem Sci. (2015) 40:248-56. doi: 10.1016/j.tibs.2015.03.001

12. Yoon JH, Abdelmohsen K, Gorospe M. Functional interactions among microRNAs and long noncoding RNAs. Semin Cell Dev Biol. (2014) 34:9-14. doi: 10.1016/j.semcdb.2014.05.015

13. You L, Wang H, Yang G, Zhao F, Zhang J, Liu Z, et al. Gemcitabine exhibits a suppressive effect on pancreatic cancer cell growth by regulating processing of PVT1 to miR1207. Mol Oncol. (2018) 12:2147-64. doi: $10.1002 / 1878-0261.12393$

14. Huppi K, Volfovsky N, Runfola T, Jones TL, Mackiewicz M, Martin $\mathrm{SE}$, et al. The identification of microRNAs in a genomically unstable region of human chromosome 8q24. Mol Cancer Res. (2008) 6:212-21. doi: 10.1158/1541-7786.MCR-07-0105

15. Beck-Engeser GB, Lum AM, Huppi K, Caplen NJ, Wang BB, Wabl M. Pvt1-encoded microRNAs in oncogenesis. Retrovirology. (2008) 5:4. doi: 10.1186/1742-4690-5-4

16. Housman G, Byler S, Heerboth S, Lapinska K, Longacre M, Snyder N, et al. Drug resistance in cancer: an overview. Cancers. (2014) 6:1769-92. doi: $10.3390 /$ cancers 6031769

17. Siegel RL, Miller KD, Jemal A. Cancer statistics, 2018. CA Cancer J Clin. (2018) 68:7-30. doi: 10.3322/caac.21442

18. Collignon J, Lousberg L, Schroeder H, Jerusalem G. Triple-negative breast cancer: treatment challenges and solutions. Breast Cancer. (2016) 8:93-107. doi: 10.2147/BCTT.S69488

19. Cortes J, Baselga J. Targeting the microtubules in breast cancer beyond taxanes: the epothilones. Oncologist. (2007) 12:271-80. doi: 10.1634/theoncologist.12-3-271

20. Jiang T, Shi W, Wali VB, Pongor LS, Li C, Lau R, et al. Predictors of chemosensitivity in triple negative breast cancer: an integrated genomic analysis. PLoS Med. (2016) 13:e1002193. doi: 10.1371/journal.pmed.1002193

21. Pena-Chilet M, Martinez MT, Perez-Fidalgo JA, Peiro-Chova L, Oltra SS, Tormo E, et al. MicroRNA profile in very young women with breast cancer. BMC Cancer. (2014) 14:529. doi: 10.1186/1471-2407-14-529

22. Lovat F, Ishii H, Schiappacassi M, Fassan M, Barbareschi M, Galligioni $\mathrm{E}$, et al. LZTS1 downregulation confers paclitaxel resistance and is associated with worse prognosis in breast cancer. Oncotarget. (2014) 5:970-7. doi: 10.18632/oncotarget.1630

23. Hou X, Niu Z, Liu L, Guo Q, Li H, Yang X, et al. miR-1207-5p regulates the sensitivity of triple-negative breast cancer cells to Taxol treatment via the suppression of LZTS1 expression. Oncol Lett. (2019) 17:990-8. doi: 10.3892/ol.2018.9687

24. Lai D, Ho KC, Hao Y, Yang X. Taxol resistance in breast cancer cells is mediated by the hippo pathway component TAZ and its downstream transcriptional targets Cyr61 and CTGF. Cancer Res. (2011) 71:2728-38. doi: 10.1158/0008-5472.CAN-10-2711

25. Nemcova-Furstova V, Kopperova D, Balusikova K, Ehrlichova M, Brynychova V, Vaclavikova R, et al. Characterization of acquired paclitaxel resistance of breast cancer cells and involvement of $\mathrm{ABC}$ transporters. Toxicol Appl Pharmacol. (2016) 310:215-28. doi: 10.1016/j.taap.2016.09.020

26. Yan C, Chen Y, Kong W, Fu L, Liu Y, Yao Q, et al. PVT1-derived miR-1207$5 p$ promotes breast cancer cell growth by targeting STAT6. Cancer Sci. (2017) 108:868-76. doi: 10.1111/cas.13212

27. Liu X, Bi L, Wang Q, Wen M, Li C, Ren Y, et al. miR-1204 targets VDR to promotes epithelial-mesenchymal transition and metastasis in breast cancer. Oncogene. (2018) 37:3426-39. doi: 10.1038/s41388-018-0215-2

28. Deeb KK, Trump DL, Johnson CS. Vitamin D signalling pathways in cancer: potential for anticancer therapeutics. Nat Rev Cancer. (2007) 7:684-700. doi: $10.1038 / \mathrm{nrc} 2196$

29. Santos-Martinez N, Diaz L, Ordaz-Rosado D, Garcia-Quiroz J, Barrera D, Avila E, et al. Calcitriol restores antiestrogen responsiveness in estrogen receptor negative breast cancer cells: a potential new therapeutic approach. BMC Cancer. (2014) 14:230. doi: 10.1186/1471-2407-14-230

30. Segovia-Mendoza M, Diaz L, Prado-Garcia H, Reginato MJ, Larrea F, Garcia-Becerra R. The addition of calcitriol or its synthetic analog EB1089 to lapatinib and neratinib treatment inhibits cell growth and promotes apoptosis in breast cancer cells. Am J Cancer Res. (2017) 7:1486-500.

31. Segovia-Mendoza M, Diaz L, Gonzalez-Gonzalez ME, Martinez-Reza I, Garcia-Quiroz J, Prado-Garcia H, et al. Calcitriol and its analogues enhance the antiproliferative activity of gefitinib in breast cancer cells. J Steroid Biochem Mol Biol. (2015) 148:122-31. doi: 10.1016/j.jsbmb.2014.12.006

32. Zinser GM, Welsh J. Vitamin D receptor status alters mammary gland morphology and tumorigenesis in MMTV-neu mice. Carcinogenesis. (2004) 25:2361-72. doi: 10.1093/carcin/bgh271

33. Zinser GM, Suckow M, Welsh J. Vitamin D receptor (VDR) ablation alters carcinogen-induced tumorigenesis in mammary gland, epidermis and lymphoid tissues. J Steroid Biochem Mol Biol. (2005) 97:153-64. doi: 10.1016/j.jsbmb.2005. 06.024

34. Dunne EF, Park IU. HPV and HPV-associated diseases. Infect Dis Clin North Am. (2013) 27:765-78. doi: 10.1016/j.idc.2013. 09.001

35. Woodman CB, Collins SI, Young LS. The natural history of cervical HPV infection: unresolved issues. Nat Rev Cancer. (2007) 7:11-22. doi: $10.1038 / \mathrm{nrc} 2050$

36. Koh WJ, Abu-Rustum NR, Bean S, Bradley K, Campos SM, Cho $\mathrm{KR}$, et al. Cervical cancer, version 3.2019, NCCN clinical practice guidelines in oncology. J Natl Compr Canc Netw. (2019) 17:64-84. doi: $10.6004 /$ jnccn.2019.0001

37. Shen CJ, Cheng YM, Wang CL. LncRNA PVT1 epigenetically silences miR195 and modulates EMT and chemoresistance in cervical cancer cells. J Drug Target. (2017) 25:637-44. doi: 10.1080/1061186X.2017.1307379

38. Massague J. TGF-beta signal transduction. Annu Rev Biochem. (1998) 67:753-91. doi: 10.1146/annurev.biochem.67.1.753

39. Zhou Q, Han LR, Zhou YX, Li Y. MiR-195 suppresses cervical cancer migration and invasion through targeting Smad3. Int J Gynecol Cancer. (2016) 26:817-24. doi: 10.1097/IGC.0000000000000686

40. Wan L, Sun M, Liu GJ, Wei CC, Zhang EB, Kong R, et al. Long noncoding RNA PVT1 promotes non-small cell lung cancer cell proliferation through epigenetically regulating LATS2 expression. Mol Cancer Ther. (2016) 15:1082-94. doi: 10.1158/1535-7163.MCT-15-0707

41. Zhou Q, Chen J, Feng J, Wang J. Long noncoding RNA PVT1 modulates thyroid cancer cell proliferation by recruiting EZH2 and regulating thyroidstimulating hormone receptor (TSHR). Tumour Biol. (2016) 37:3105-13. doi: 10.1007/s13277-015-4149-9

42. Guo J, Hao C, Wang C, Li L. Long noncoding RNA PVT1 modulates hepatocellular carcinoma cell proliferation and apoptosis by recruiting EZH2. Cancer Cell Int. (2018) 18:98. doi: 10.1186/s12935-018-0582-3 
43. Zhang S, Zhang G, Liu J. Long noncoding RNA PVT1 promotes cervical cancer progression through epigenetically silencing miR-200b. APMIS. (2016) 124:649-58. doi: 10.1111/apm.12555

44. Gao YL, Zhao ZS, Zhang MY, Han LJ, Dong YJ, Xu B. Long Noncoding RNA PVT1 facilitates cervical cancer progression via negative regulating of miR424. Oncol Res. (2017) 25:1391-8. doi: 10.3727/096504017X14881559833562

45. Sharma S, Mandal P, Sadhukhan T, Roy Chowdhury R, Ranjan Mondal N, Chakravarty B, et al. Bridging links between long noncoding RNA HOTAIR and HPV oncoprotein E7 in cervical cancer pathogenesis. Sci Rep. (2015) 5:11724. doi: 10.1038/srep11724

46. Dong J, Su M, Chang W, Zhang K, Wu S, Xu T. Long non-coding RNAs on the stage of cervical cancer (Review). Oncol Rep. (2017) 38:1923-31. doi: 10.3892/or.2017.5905

47. Testa U, Castelli G, Pelosi E. Lung cancers: molecular characterization, clonal heterogeneity and evolution, and cancer stem cells. Cancers (Basel). (2018) 10:E248. doi: 10.3390/cancers 10080248

48. Koberle B, Tomicic MT, Usanova S, Kaina B. Cisplatin resistance: preclinical findings and clinical implications. Biochim Biophys Acta. (2010) 1806:17282. doi: 10.1016/j.bbcan.2010.07.004

49. Galluzzi L, Vitale I, Michels J, Brenner C, Szabadkai G, Harel-Bellan A, et al. Systems biology of cisplatin resistance: past, present and future. Cell Death Dis. (2014) 5:e1257. doi: 10.1038/cddis.2013.428

50. Dasari S, Tchounwou PB. Cisplatin in cancer therapy: molecular mechanisms of action. Eur J Pharmacol. (2014) 740:364-78. doi: 10.1016/j.ejphar.2014.07.025

51. Chen L, Han X, Hu Z, Chen L. The PVT1/miR-216b/Beclin-1 regulates cisplatin sensitivity of NSCLC cells via modulating autophagy and apoptosis. Cancer Chemother Pharmacol. (2019) 83:921-31. doi: 10.1007/s00280-019-03808-3

52. Liu G, Pei F, Yang F, Li L, Amin AD, Liu S, et al. Role of autophagy and apoptosis in non-small-cell lung cancer. Int J Mol Sci. (2017) 18:E367. doi: 10.3390/ijms 18020367

53. Zhou W, Yue C, Deng J, Hu R, Xu J, Feng L, et al. Autophagic protein Beclin 1 serves as an independent positive prognostic biomarker for non-small cell lung cancer. PLoS ONE. (2013) 8:e80338. doi: 10.1371/journal.pone.0080338

54. Luo $\mathrm{M}$, Wu L, Zhang $\mathrm{K}$, Wang $\mathrm{H}$, Wu S, O'Connell $\mathrm{D}$, et al. miR-216b enhances the efficacy of vemurafenib by targeting Beclin1, UVRAG and ATG5 in melanoma. Cell Signal. (2018) 42:30-43. doi: 10.1016/j.cellsig.2017.09.024

55. Zhang Y, Yang WQ, Zhu H, Qian YY, Zhou L, Ren YJ, et al. Regulation of autophagy by miR-30d impacts sensitivity of anaplastic thyroid carcinoma to cisplatin. Biochem Pharmacol. (2014) 87:562-70. doi: 10.1016/j.bcp.2013.12.004

56. Wu D, Li Y, Zhang H, Hu X. Knockdown of Lncrna PVT1 Enhances Radiosensitivity in non-small cell lung cancer by sponging Mir-195. Cell Physiol Biochem. (2017) 42:2453-66. doi: 10.1159/000480209

57. Guo D, Wang Y, Ren K, Han X. Knockdown of LncRNA PVT1 inhibits tumorigenesis in non-small-cell lung cancer by regulating miR-497 expression. Exp Cell Res. (2018) 362:172-9. doi: 10.1016/j.yexcr.2017.11.014

58. Wang C, Han C, Zhang Y, Liu F. LncRNA PVT1 regulate expression of HIF1alpha via functioning as ceRNA for miR199a5p in nonsmall cell lung cancer under hypoxia. Mol Med Rep. (2018) 17:1105-10. doi: 10.3892/mmr.2017.7962

59. Wang $\mathrm{D}, \mathrm{Hu}$ Y. Long Non-coding RNA PVT1 competitively binds MicroRNA-424-5p to regulate CARM1 in radiosensitivity of nonsmall-cell lung cancer. Mol Ther Nucleic Acids. (2018) 16:130-40. doi: 10.1016/j.omtn.2018.12.006

60. Qin S, Zhao Y, Lim G, Lin H, Zhang X, Zhang X. Circular RNA PVT1 acts as a competing endogenous RNA for miR-497 in promoting non-small cell lung cancer progression. Biomed Pharmacother. (2019) 111:244-50. doi: 10.1016/j.biopha.2018.12.007

61. Jiang W, He Y, Shi Y, Guo Z, Yang S, Wei K, et al. MicroRNA-1204 promotes cell proliferation by regulating PITX1 in non-small-cell lung cancer. Cell Biol Int. (2019) 43:253-64. doi: 10.1002/cbin.11083

62. Misaghi A, Goldin A, Awad M, Kulidjian AA. Osteosarcoma: a comprehensive review. SICOT J. (2018) 4:12. doi: 10.1051/sicotj/2017028

63. Palmerini E, Jones RL, Marchesi E, Paioli A, Cesari M, Longhi A, et al. Gemcitabine and docetaxel in relapsed and unresectable high-grade osteosarcoma and spindle cell sarcoma of bone. BMC Cancer. (2016) 16:280. doi: 10.1186/s12885-016-2312-3

64. Sun ZY, Jian YK, Zhu HY, Li B. IncRNAPVT1 targets miR-152 to enhance chemoresistance of osteosarcoma to gemcitabine through activating c-MET/PI3K/AKT pathway. Pathol Res Pract. (2019) 215:555-63. doi: 10.1016/j.prp.2018.12.013

65. Wang K, Zhuang Y, Liu C, Li Y. Inhibition of c-Met activation sensitizes osteosarcoma cells to cisplatin via suppression of the PI3K-Akt signaling. Arch Biochem Biophys. (2012) 526:38-43. doi: 10.1016/j.abb.2012.07.003

66. Li M, Li Z, Wang X, Wang Y, Zhao C, Wang L. Function of miR152 as tumor suppressor in oral squamous cell carcinoma cells by targeting cMET. Oncol Rep. (2018) 39:1173-80. doi: 10.3892/or.2017.6157

67. Kun-Peng Z, Xiao-Long M, Chun-Lin Z. Overexpressed circPVT1, a potential new circular RNA biomarker, contributes to doxorubicin and cisplatin resistance of osteosarcoma cells by regulating ABCB1. Int J Biol Sci. (2018) 14:321-30. doi: 10.7150/ijbs.24360

68. Song J, Wu X, Liu F, Li M, Sun Y, Wang Y, et al. Long non-coding RNA PVT1 promotes glycolysis and tumor progression by regulating miR-497/HK2 axis in osteosarcoma. Biochem Biophys Res Commun. (2017) 490:217-24. doi: 10.1016/j.bbrc.2017.06.024

69. Zhou Q, Chen F, Zhao J, Li B, Liang Y, Pan W, et al. Long noncoding RNA PVT1 promotes osteosarcoma development by acting as a molecular sponge to regulate miR-195. Oncotarget. (2016) 7:82620-33. doi: 10.18632/oncotarget.13012

70. Li D, O'Reilly EM. Adjuvant and neoadjuvant systemic therapy for pancreas adenocarcinoma. Semin Oncol. (2015) 42:134-43. doi: 10.1053/j.seminoncol.2014.12.012

71. You L, Chang D, Du HZ, Zhao YP. Genome-wide screen identifies PVT1 as a regulator of Gemcitabine sensitivity in human pancreatic cancer cells. Biochem Biophys Res Commun. (2011) 407:1-6. doi: 10.1016/j.bbrc.2011.02.027

72. Gilbert-Ross M, Marcus AI, Zhou W. RhoA, a novel tumor suppressor or oncogene as a therapeutic target? Genes Dis. (2015) 2:2-3. doi: 10.1016/j.gendis.2014.10.001

73. Zhang X, Feng W, Zhang J, Ge L, Zhang Y, Jiang X, et al. Long noncoding RNA PVT1 promotes epithelialmesenchymal transition via the TGFbeta/Smad pathway in pancreatic cancer cells. Oncol Rep. (2018) 40:1093-102. doi: 10.3892/or.2018.6462

74. Lazcano-Ponce EC, Miquel JF, Munoz N, Herrero R, Ferrecio C, Wistuba, II, et al. Epidemiology and molecular pathology of gallbladder cancer. $C A$ Cancer J Clin. (2001) 51:349-64. doi: 10.3322/canjclin.51.6.349

75. Saika K, Machii R. Five-year relative survival rate of gallbladder cancer in the USA, Europe and Japan. Jpn J Clin Oncol. (2014) 44:704. doi: 10.1093/jjco/hyu087

76. Zhu AX, Hong TS, Hezel AF, Kooby DA. Current management of gallbladder carcinoma. Oncologist. (2010) 15:168-81. doi: 10.1634/theoncologist.2009-0302

77. Shen ED, Liu B, Yu XS, Xiang ZF, Huang HY. The effects of miR1207-5p expression in peripheral blood on cisplatin-based chemosensitivity of primary gallbladder carcinoma. Onco Targets Ther. (2016) 9:3633-42. doi: 10.2147/OTT.S101310

78. Chen J, Yu Y, Li H, Hu Q, Chen X, He Y, et al. Long noncoding RNA PVT1 promotes tumor progression by regulating the miR-143/HK2 axis in gallbladder cancer. Mol Cancer. (2019) 18:33. doi: 10.1186/s12943-019-0947-9

79. Landgraf P, Rusu M, Sheridan R, Sewer A, Iovino N, Aravin A, et al. A mammalian microRNA expression atlas based on small RNA library sequencing. Cell. (2007) 129:1401-14. doi: 10.1016/j.cell.2007. 04.040

80. Peschiaroli A, Giacobbe A, Formosa A, Markert EK, Bongiorno-Borbone L, Levine AJ, et al. miR-143 regulates hexokinase 2 expression in cancer cells. Oncogene. (2013) 32:797-802. doi: 10.1038/onc.2012.100

81. Bray F, Ferlay J, Soerjomataram I, Siegel RL, Torre LA, Jemal A. Global cancer statistics 2018: GLOBOCAN estimates of incidence and mortality worldwide for 36 cancers in 185 countries. CA Cancer J Clin. (2018) 68:394-424. doi: 10.3322/caac. 21492

82. Finn RS, Zhu AX, Farah W, Almasri J, Zaiem F, Prokop LJ, et al. Therapies for advanced stage hepatocellular carcinoma with macrovascular invasion or 
metastatic disease: a systematic review and meta-analysis. Hepatology. (2018) 67:422-35. doi: 10.1002/hep.29486

83. Ding C, Yang Z, Lv Z, Du C, Xiao H, Peng C, et al. Long noncoding RNA PVT1 is associated with tumor progression and predicts recurrence in hepatocellular carcinoma patients. Oncol Lett. (2015) 9:955-63. doi: 10.3892/ol.2014.2730

84. Lan T, Yan X, Li Z, Xu X, Mao Q, Ma W, et al. Long non-coding RNA PVT1 serves as a competing endogenous RNA for miR-186-5p to promote the tumorigenesis and metastasis of hepatocellular carcinoma. Tumour Biol. (2017) 39:1010428317705338. doi: 10.1177/1010428317705338

85. Zhang Y, Wen DY, Zhang R, Huang JC, Lin P, Ren FH, et al. A preliminary investigation of PVT1 on the effect and mechanisms of hepatocellular carcinoma: evidence from clinical data, a meta-analysis of 840 cases, and in vivo validation. Cell Physiol Biochem. (2018) 47:2216-32. doi: 10.1159/000491534

86. Tang LL, Chen WQ, Xue WQ, He YQ, Zheng RS, Zeng YX, et al. Global trends in incidence and mortality of nasopharyngeal carcinoma. Cancer Lett. (2016) 374:22-30. doi: 10.1016/j.canlet.2016.01.040

87. Jia WH, Huang QH, Liao J, Ye W, Shugart YY, Liu Q, et al. Trends in incidence and mortality of nasopharyngeal carcinoma over a 20-25 year period (1978/1983-2002) in Sihui and Cangwu counties in southern China. BMC Cancer. (2006) 6:178. doi: 10.1186/1471-2407-6-178

88. Chen YP, Chan ATC, Le QT, Blanchard P, Sun Y, Ma J. Nasopharyngeal carcinoma. Lancet. (2019) 394:64-80. doi: 10.1016/S0140-6736(19)30956-0

89. Peng X, Cao P, Li J, He D, Han S, Zhou J, et al. MiR-1204 sensitizes nasopharyngeal carcinoma cells to paclitaxel both in vitro and in vivo. Cancer Biol Ther. (2015) 16:261-7. doi: 10.1080/15384047.2014.1001287

90. Kim S, Han Y, Kim SI, Kim HS, Kim SJ, Song YS. Tumor evolution and chemoresistance in ovarian cancer. NPJ Precis Oncol. (2018) 2:20. doi: 10.1038/s41698-018-0063-0

91. Li SS, Ma J, Wong AST. Chemoresistance in ovarian cancer: exploiting cancer stem cell metabolism. J Gynecol Oncol. (2018) 29:e32. doi: 10.3802/jgo.2018.29.e32

92. Cornelison R, Llaneza DC, Landen CN. Emerging therapeutics to overcome chemoresistance in epithelial ovarian cancer: a mini-review. Int J Mol Sci. (2017) 18:E2171. doi: 10.3390/ijms18102171

93. Wu G, Liu A, Zhu J, Lei F, Wu S, Zhang X, et al. MiR-1207 overexpression promotes cancer stem cell-like traits in ovarian cancer by activating the Wnt/beta-catenin signaling pathway. Oncotarget. (2015) 6:28882-94. doi: 10.18632/oncotarget.4921

94. Steg AD, Bevis KS, Katre AA, Ziebarth A, Dobbin ZC, Alvarez RD, et al. Stem cell pathways contribute to clinical chemoresistance in ovarian cancer. Clin Cancer Res. (2012) 18:869-81. doi: 10.1158/1078-0432.CCR-11-2188

95. Chau WK, Ip CK, Mak AS, Lai HC, Wong AS. c-Kit mediates chemoresistance and tumor-initiating capacity of ovarian cancer cells through activation of Wnt/beta-catenin-ATP-binding cassette G2 signaling. Oncogene. (2013) 32:2767-81. doi: 10.1038/onc.2012.290

96. Saraon P, Drabovich AP, Jarvi KA, Diamandis EP. Mechanisms of androgenindependent prostate cancer. EJIFCC. (2014) 25:42-54.

97. Feldman BJ, Feldman D. The development of androgen-independent prostate cancer. Nat Rev Cancer. (2001) 1:34-45. doi: 10.1038/35094009
98. Das DK, Naidoo M, Ilboudo A, Park JY, Ali T, Krampis K, et al. miR-1207-3p regulates the androgen receptor in prostate cancer via FNDC1/fibronectin. Exp Cell Res. (2016) 348:190-200. doi: 10.1016/j.yexcr.2016.09.021

99. Liu HT, Fang L, Cheng YX, Sun Q. LncRNA PVT1 regulates prostate cancer cell growth by inducing the methylation of miR-146a. Cancer Med. (2016) 5:3512-9. doi: 10.1002/cam4.900

100. Murugan AK, Munirajan AK, Alzahrani AS. Long noncoding RNAs: emerging players in thyroid cancer pathogenesis. Endocr Relat Cancer. (2018) 25:R59-82. doi: 10.1530/ERC-17-0188

101. Zhang R, Hardin H, Huang W, Buehler D, Lloyd RV. Long non-coding RNA Linc-ROR Is upregulated in papillary thyroid carcinoma. Endocr Pathol. (2018) 29:1-8. doi: 10.1007/s12022-0179507-2

102. Feng K, Liu Y, Xu LJ, Zhao LF, Jia CW, Xu MY. Long noncoding RNA PVT1 enhances the viability and invasion of papillary thyroid carcinoma cells by functioning as ceRNA of microRNA-30a through mediating expression of insulin like growth factor 1 receptor. Biomed Pharmacother. (2018) 104:68698. doi: 10.1016/j.biopha.2018.05.078

103. Ping G, Xiong W, Zhang L, Li Y, Zhang Y, Zhao Y. Silencing long noncoding RNA PVT1 inhibits tumorigenesis and cisplatin resistance of colorectal cancer. Am J Transl Res. (2018) 10:138-49. doi: 10.1080/01635581.2019.1650192

104. Zhang XW, Bu P, Liu L, Zhang XZ, Li J. Overexpression of long noncoding RNA PVT1 in gastric cancer cells promotes the development of multidrug resistance. Biochem Biophys Res Commun. (2015) 462:227-32. doi: 10.1016/j.bbrc.2015.04.121

105. Wang Z, Su M, Xiang B, Zhao K, Qin B. Circular RNA PVT1 promotes metastasis via miR-145 sponging in CRC. Biochem Biophys Res Commun. (2019) 512:716-22. doi: 10.1016/j.bbrc.2019.03.121

106. Li X, Zhang Z, Jiang H, Li Q, Wang R, Pan H, et al. Circular RNA circPVT1 promotes proliferation and invasion through sponging miR-125b and activating E2F2 signaling in non-small cell lung cancer. Cell Physiol Biochem. (2018) 51:2324-40. doi: 10.1159/000495876

107. Chen J, Li Y, Zheng Q, Bao C, He J, Chen B, et al. Circular RNA profile identifies circPVT1 as a proliferative factor and prognostic marker in gastric cancer. Cancer Lett. (2017) 388:208-19. doi: 10.1016/j.canlet.2016. 12.006

Conflict of Interest Statement: OO is a co-founder of NucleoBio, Inc., a City University of New York start-up biotechnology company.

The remaining author declares that the research was conducted in the absence of any commercial or financial relationships that could be construed as a potential conflict of interest.

Copyright (C) 2019 Ogunwobi and Kumar. This is an open-access article distributed under the terms of the Creative Commons Attribution License (CC BY). The use, distribution or reproduction in other forums is permitted, provided the original author(s) and the copyright owner(s) are credited and that the original publication in this journal is cited, in accordance with accepted academic practice. No use, distribution or reproduction is permitted which does not comply with these terms. 